\title{
Sediment-hosted gas hydrates: new insights on natural and synthetic systems
}

\author{
Q11 \\ D. A. $\mathrm{LONG}^{1}$, M. A. LOVELL 2 , J. G. REES ${ }^{3}$ \& C. A. ROCHELLE 3 \\ ${ }^{1}$ British Geological Survey, West Mains Road, Edinburgh EH9 3LA, UK \\ ${ }^{2}$ Department of Geology, University of Leicester, Leicester LE1 7RH, UK \\ ${ }^{3}$ British Geological Survey, Kingsley Dunham Centre, Keyworth, Nottingham NG12 5GG, UK
}

Over recent decades hydrates have been gradually making their way up the scientific agenda, receiving correspondingly greater wider societal interest with time. However, what is most notable to the casual observer is not the fact that it is broadly recognized that hydrates have the potential to be a major environmental hazard or a major new energy source, but that nobody is exactly shouting about it. There are several reasons for this. Geological investigations suggest that hydrates were at least partners in crime in many climatic disasters, such as the great methane outbursts that caused the mass extinctions at the end of the Permian (Erwin 1994; Krull \& Retallack 2000) or Palaeocene (Dickens et al. 1997). Whilst people are interested in such events, the immediate instability of possibly 'lifethreatening' natural hydrates does not seem to be their immediate concern; it is clear that they occurred a long time ago, since when environments have greatly changed, and it is also apparent that they were largely precipitated by external triggers (White 2002; Maclennan \& Jones 2006). Likewise, although they see the potential to produce energyproviding methane from hydrates, initial difficulties in doing so have dampened interest. In both cases as a hazard or resource - the lack of societal focus largely stems from the body language of the scientific community, which is itself highly uncertain of the importance of hydrates. Scientists are not certain enough of their ground to allow a clear direction to be mapped in relation to minimization of the risk of mass hydrate destablization or widespread exploitation. To a large degree this uncertainty centres on our poor fundamental understanding of the occurrence and stability of sediment-hosted hydrates. There is no better illustration of this than the widely fluctuating predictions of global hydrate reserves we have seen in recent years, where estimates vary between $10^{15}$ and $10^{19} \mathrm{~m}^{3}$ of methane gas at STP. Milkov (2003) describes how improved understanding of the distribution and concentration of gas hydrates in marine sediments has led to a readjustment of global estimates downwards over each subsequent decade, although the estimate of $10^{15} \mathrm{~m}^{3}$ is challenged by Klauda \& Sandler (2005), who suggest that a total volume of $10^{17} \mathrm{~m}^{3}$ is likely with $10^{16} \mathrm{~m}^{3}$ located on continental margins. Although there is starting to be a consensus in the order of $10^{16} \mathrm{~m}^{3}$ (e.g. Kvenvolden 1998, 2000; Makogon et al. 2007), a range of values are still used and such apparent uncertainty in hydrate abundance hardly conveys the message to the wider community that the scientists know what they are talking about.

To move this debate along, we considered the source of our greatest uncertainties and found that these largely centre around how hydrates are physically stored in sediments at a range of scales. At present our understanding is extremely crude. We have very little knowledge about how hydrates are stored in sediments of different grain size or texture, whether they dominantly are separated by water films in inter-grain pores, or whether they coat grains, how bacteria control authigenic fixation, and whether the mineralogy of host-sediment influences the microscale sediment-hydrate association. At a larger scale, we have a very poor understanding of the distribution of hydrates within individual beds, let alone complex heterolithic sequences. Big questions prevail. Do hydrates form pods that are little influenced by lithology as in many ore bodies, or are they dominantly stratiform and follow rules of behaviour that are analogous to hydrocarbons in reservoirs? How much are sediment-hosted distributions controlled by structural settings, whether tectonic, gravitational or through diagenetic changes in the sediment (for instance the development of cavities or veins through shrinkage)? It is clear that our ability to describe such relationships is very immature, even before we start to make sense of changing pressure, temperature and salinity regimes, as well as the variation in natural supply of methane from external sources.

To review our current understanding, and in order to encourage debate about these issues, we decided to convene a meeting to which interested 
scientists could look at these many challenges in a fairly relaxed setting. Consequently, with the support of the Geological Society Hydrocarbons Group, a two-day meeting 'Sediment-Hosted Gas Hydrates: New Insights on Natural and Synthetic Systems' took place at Burlington House, Piccadilly, London on 25-26 January 2006. This was based on 35 presentations and posters and brought together over about 100 international hydrate scientists spanning the hazard and resource communities, as well as those with very different experience, for instance those involved principally with laboratory experimentation, mixing with those of geophysical field studies or geochemical mapping. The main theme of the meeting was the nature of the primary hydrate-sediment relationships that control hydrate stability. This largely addressed the distribution of natural sediment-hosted hydrates, but also covered research into synthetic systems. The latter are of interest as they provide analogues of natural environments, but in very well calibrated, controlled laboratory settings where textural relationships and processes can be mapped and measured. Synthetic sediment-hosts are also likely to be of interest in the future as a possible store of greenhouse gases; the possibility that hydrates could be used to store large volumes of human-generated carbon dioxide was discussed at some length in the meeting. The structure and content of this volume largely reflects the structure and interests of the meeting and addresses sediment-hosted hydrates in natural and synthetic systems separately.

\section{Natural systems}

\section{Setting of natural hydrates}

The study of hydrates began as that of a curiosity in the nineteenth century (Davy, 1811) and then as a practical solution to difficulties in transporting gas by pipeline in the early twentieth century (Hammerschmidt 1934). Once it was realized that the pressure and temperature conditions necessary for methane hydrate formation exist naturally, the hunt was on to locate examples. In the 1960s and 1970s hydrate was identified in wells drilled through the Siberian and Alaskan permafrost (Collett 1983), and samples of hydrate were recovered from the Black Sea in 1974 (Yeframova \& Zhizhchenko 1975) and then many other deep water settings. A few years previously, bottom simulating reflectors (BSRs) were identified and attributed to the occurrence of methane hydrates (Lancelot \& Ewing 1972); hydrates have subsequently been recognized on many continental slopes around the world. Recent evidence suggests, however, that the presence of BSRs alone is, however, not a reliable indicator of the presence or not of methane hydrates (Finley \& Kranson 1986). In particular BSRs form at the interface between hydrate and free gas, but in the absence of free gas a BSR will not develop, even if hydrates are present (Haq 1998). Similarly other cross cutting reflectors can be formed by diagenetic processes (Davies \& Cartwright 2002). Therefore careful analysis needs to be of conducted of BSRs before attributing extensive areas of continental slopes as hydrate bearing. Because of the unreliability of much of the BSR evidence, even our local estimates of hydrate volume are highly uncertain. For example, in the Gulf of Mexico, where they are of both biogenic and petrogenic origin and have been found even at the seabed, Collet \& Kuuskraa (1998) estimated that up to 500 Gton of carbon occurred as hydrate but Milkov \& Sassen (2001) estimated only 5 Gton of carbon. Even if the relationship between BSRs and hydrates were well established, the fact that the reported occurrence is strongly influenced by the identification of BSRs in geophysical surveys conducted for hydrocarbon exploration, suggests that we are likely to have a poor understanding of the real distribution of hydrates. Although many areas can be shown to have the appropriate temperature and pressure conditions, they are lacking physical samples or geophysical evidence. Many of these problems are discussed by Kleinberg (2009), who discusses the problems of exploring for hydrates and suggests adaptations to geological and geophysical survey methods.

\section{Characteristic hydrate domains}

The primary source of methane in hydrate deposits is biogenic decay of organic matter, as demonstrated by the isotopic composition and the near absence of higher hydrocarbons such as ethane and propane (Kvenvolden \& McDonald 1985). Although hydrates of a petrogenic (thermogenic) origin have been encountered in many hydrocarbon basins (e.g. the Gulf of Mexico or Caspian Sea), they appear to be less common (Brooks \& Bryant 1985; Soloviev \& Ginsberg 1994). In the former a greater range of hydrates are present, including ethane and propane hydrates, which result in different hydrate structures and different interactions with the associated sediments. Hydrate can occur in various forms. The main type is stratigraphic-type hydrate deposits (Milkov \& Sassen 2001) formed at the base of the Q1 hydrate stability zone (HSZ), where there is the greatest concentration of hydrate due to methane generation within sedimentary units. Structural-type hydrate deposits form where methane migration through faults allows hydrate to occur at all points within the HSZ, including near the seabed where it is vulnerable to changes in bottom water conditions. Mazurenko et al. (2009) describe one such seabed 
site in the Sea of Okhotsk where hydrate is forming rapidly at the present time in areas of focused fluid flow. They used isotopic and chemical approaches to ascertain that fluids from depth have interacted with porewaters within shallow sediments and led to the formation of hydrates. The establishment of seabed observatories, as described by McGee $\boldsymbol{e t}$ al. (2009), will allow detailed monitoring of the growth and decay of these features and the interaction with the biosphere. It was originally presumed that hydrate occurred as thick layers often within fine-grained sediments. Increasingly the evidence suggests that hydrate preferentially occurs as layers within coarse-grained sediments due to the greater permeability of these horizons (Clennell et al. 1999). More recently, evidence has shown that hydrate occurs along fractures, indicating the flow of methane and other gases into and through the hydrate stability zone; recent recovery of hydrate-bearing cores under in-situ pressure (Schultheiss pers. comm.) from Hydrate Ridge and offshore-India, using HYACE equipment, has allowed X-ray identification of hydrate filled fractures.

A concern raised as a consequence of the increasing interest in climate change is the presence of hydrate occurring under permafrost. With rising temperatures the breakdown of permafrost systems is predicted; these are likely to have an increased potential to release methane, thereby providing positive feedbacks to climate change. The Arctic coastlines and shelf seas of Siberia, Alaska and Canada are the focus of this concern, although this assumes that methane hydrate is trapped beneath the permafrost. For such circumstances to prevail it is expected that a relatively thick permafrost will produce sufficiently low temperatures at high enough pressures for hydrate to be stable below it. However, there is some evidence (Yakushev 2004) that methane hydrate can exist within permafrost at shallower depths, in regions where it is only metastable, and thus especially vulnerable to climate change. In some cases, it is likely that great volumes of methane as free gas may occur under a 'cap' of permafrost or hydrate, and there is the potential for this to be released should increasing temperatures melt the permafrost or disassociate hydrate. Climate change is also likely to impact on hydrate stability in other settings. The warming of oceans has been identified as a potential concern as increases in bottom water temperatures will lead to the displacement of the underlying geothermal profile and a reduction in the dimensions of the hydrate stability zone. Recent warming of the oceans has been attributed to anthropogenic greenhouse gas Q2 emissions (Levitus et al. 2005). However it is expected that changes in water temperature will be greatest in areas of shallower seas, thereby making submarine hydrates in polar shelf regions more vulnerable than elsewhere.

Submarine slope failures have been attributed to former changes in the stability regime. Examples of these mass movements are reported by Swart (2009) from the Namibian margin where hydrates are closely associated with the slump deposits. With future changes in seabed conditions now locked in due to recent and predicted changes in global temperatures, further failures may occur.

\section{Sediment-hydrate interaction}

Malone (1985) describes four possible hydrate morphologies with the terminology disseminated, nodular, vein and massive. Disseminated hydrate occurs within the pore space of the sediment, while the other three occur where the sediment is disturbed either by regional tectonic stresses or through the stress resulting from hydrate crystal growth - for instance Cook and Goldberg (2007) found hydrate bearing fractures to be oriented with respect to regional tectonic stresses offshore India. Whilst such observational classifications may have had some merit (even though they have commonly been based on limited observations of natural hydrate samples recovered intact in sediment samples, and often these were in the process of undergoing dissociation by the time of the observation), they have done little to further our understanding of sediment-hydrate interactions.

Theoretical work on hydrate formation (Clennell et al. 1999; Henry et al. 1999) explored the influence of capillary pressure and thermodynamics on hydrate growth and provided some real physical constraints to hydrate morphology. It concluded that hydrate growth in fine-grained muds would be unlikely, and that coarser-grained sediments, exhibiting larger pores, would act as more likely hosts. Thus theoretical consideration suggested that hydrate morphology is controlled by the nature of the sediment host as much as by the supply of the necessary 'ingredients' and conditions (water, gas, nucleation sites, temperature and pressure). This theoretical work is also supported by experimental studies (Kleinberg et al. 2003; Camps 2007) and by observations (e.g. Tréhu et al. 2002; Riedel et al. 2006) where disseminated hydrate is limited to coarser-grained sediments and the other forms tend to occur in finer-grained sediments where the sediment fabric is disturbed. Similar observations were found through investigations of hydrate dissociation conditions (Anderson et al. 2003; Llamedo et al. 2004). These revealed that dissociation is more readily achieved within small pores compared with large pores, suggesting the possibility of hydrate breakdown in small pores though not in adjacent large pores. Tréhu et al. 
(2004) discuss how the distribution of gas hydrate is controlled both structurally and stratigraphically, and that high concentrations are limited to close to the upper tens of metres for the Cascadia Margin (at greater depths concentrations are rarely more than $2 \%$ ). The role of the subsea biosphere on hydrate formation and distribution is largely unknown, though Inagaki et al. (2006) found that, for two separate locations in the Pacific, prokaryotic communities in methane hydrate-bearing sediment cores are distinct from those in hydrate-free cores.

Significant advances in characterization of the relationship between sediments and hydrates have been recently developed. For instance, Tinivella et al. (2009) have quantified the concentrations of gas hydrate in pore space by travel-time inversion modelling of the acoustic properties of these sediments. Such analysis has allowed the identification of free gas distribution in pore spaces, likely patterns of fluid migration, the physical properties of sediments and the consequent origin of the BSR offshore the Antarctic Peninsula. At other sites, where other geophysical approaches have been applicable, hydrate volumes have often been estimated using electrical or acoustic measurements and relating these parameters (electrical resistivity and acoustic velocity) to the hydrate concentration or saturation in the pore space. Such transforms usually assume the hydrate is disseminated in the pore space and that the sediment remains water wet, rather as for petroleum-bearing reservoirs. However, Ecker et al. (2000) and Dvorkin et al. (2000) demonstrate that knowledge of the interaction between hydrate and sediment grains is crucial in achieving wellconstrained volume estimates of hydrate. It is also recognized that the use of Archie's equations assumes the hydrate does not completely block off the pore space at low saturations, treating hydrate as a hydrocarbon fluid. Minshull \& Chand (2009) further refine the self-consistent approximation/ differential effective medium approach relating seismic properties of sediment to its hydrate content. Their results suggest that the inferred proportion of load-bearing hydrate appears to decrease with increasing hydrate saturation for gas-rich laboratory environments, but increase when hydrate is formed from solution.

Koh \& Sloan (2007) suggest there has been a recent paradigm shift from addressing the thermodynamics (i.e. time-independent properties) to hydrate formation and dissociation kinetics. Thus improved understanding of these processes is crucial if there is to be any control of gas recovery from hydrates in-situ or in assessing hydrate dissolution and ensuing environmental impact. Understanding the size and morphology of hydrates is central to modelling these processes. The paper by Klapp et $\boldsymbol{a l}$. (2009) adds to our knowledge in this area through the use of high-energy Synchrotron diffraction to determine grain sizes of six natural gas hydrates in samples retrieved from the Bush Hill region in the Gulf of Mexico and from ODP Leg 204 at the Hydrate Ridge offshore Oregon.

\section{Stability of methane hydrates}

It is clear that naturally changing conditions over geologic timescales have forced the formation and disassociation of vast amounts of methane hydrate on Earth, with individual volumes of rock possibly having experienced several episodes of conditions favouring hydrate stability. A detailed knowledge of hydrate stability is thus important in terms of understanding and quantifying carbon cycling and methane release in the geologic record (e.g. events in the PETM; Sluijs 2006), and especially so in the light of anthropogenic influences on the global climate.

Many studies have made detailed measurements of the stability of methane hydrates under different pressure and temperature conditions, and with different fluid composition. Such investigations have often been driven by the needs of the hydrocarbon industry, as hydrate formation within boreholes or surface infrastructure can impact production and the safety of operations. Compilations of data resulting from such studies (e.g. Sloan 1998) have led to the production of computer codes that can be used to model hydrate stability over a broad range of conditions. They can also be used in scoping calculations to 'map out' hydrate stability zones within sediments.

It is not necessarily straightforward however, to apply data from relatively open systems (effectively having 'huge' pore spaces), to fine-grained sediments. Indeed, previous studies (e.g. Clennell et al. 1999; Henry et al. 1999; Llamedo et al. 2004) show that the pressure-temperature stability field of methane hydrate is reduced in very narrow pores. The study by Anderson et al. (2009) takes these observations further, by considering the effect of narrow pores on hydrate growth, as well as dissociation. For narrow pores they find a distinct hysteresis over a range of pressure-temperature conditions during cycles of hydrate growth and disassociation, with hydrate formation occurring at significantly lower temperatures (or higher pressures) compared with dissociation.

There are other processes, however, that occur even when samples of hydrate are kept within their stability zone. Although these may not alter the overall stability of the total mass of hydrate present, they may act to alter its distribution. One such process described by Klapp et al. (2009) is where larger hydrate crystals grow at the expense of smaller ones. A consequence of this is that over 
time the average size of hydrate crystals within a sample increases; Klapp et al. (2009) suggest that advanced X-ray techniques may be one way to assess such size changes. Given further development and calibration against hydrate samples of known ages, it may even be possible to use ratedependant information such as this to make estimates of the age of hydrate samples. Some of these approaches have been developed by Eaton $\boldsymbol{e t} \boldsymbol{a l}$. (2009), who explore two hydrate formation methods, based on depleted sediment samples from Blake Ridge using a flexible unit that records temperatures, pressures and changes in gas volume during absorption/evolution: (1) under continuous methane gasflow conditions; and (2) where hydrates are formed from the dissolved gas phase by diffusion.

Studies such as those outlined above are very important when considering sediment-hosted gas hydrates as they will impact upon our predictions of hydrate stability; such work needs to continue, to advance our knowledge in this area. Indeed, accurate assessments of hydrate stability will have to consider the characteristics of the host sediment as well as pressure, temperature and fluid composition. Not only could such analysis alter estimates of natural methane hydrate abundance in (or recovery from) fine-grained sediments, but it could also enhance the estimate of other hydrates in anthropogenic systems - such as during the underground storage of carbon dioxide.

\section{Synthetic systems}

\section{Carbon dioxide hydrates}

As a consequence of the abundance and importance of methane hydrate, be it formed naturally in sediments or within engineered structures such as pipelines, most studies of sediment-hosted hydrates have focussed on methane hydrate systems. However, other sediment-hosted hydrates can also be important in certain circumstances, and one example is $\mathrm{CO}_{2}$ hydrate. Although the occurrence of natural $\mathrm{CO}_{2}$ hydrate is rare (e.g. Sakai et al. 1990), its controlled formation and storage could provide a mechanism with which to trap and store waste $\mathrm{CO}_{2}$ rather than emit it to the atmosphere. This approach is very relevant to current discussions about the degree of anthropogenic influence on climate and how it might be reduced (e.g. IPCC 1990, 1995, 2001, 2007; RCEP 2000). Indeed, reducing overall anthropogenic releases of $\mathrm{CO}_{2}$ may be vital to limit the extent of global warming, and hence reduce the potential for climate-induced breakdown of vast amounts of natural methane hydrate from permafrost areas or below the sea floor.

Ongoing industrial-scale projects at places such as Sleipner (North Sea) (Baklid et al. 2006) and
Weyburn (Canada) (Malk \& Islam 2000; White et al. 2004; Wilson \& Monea 2004) demonstrate the practicality of capturing large amounts of $\mathrm{CO}_{2}$ and injecting it within deep, warm sediments to be eventually trapped either dissolved in solution or as carbonate minerals (e.g. Bachu et al. 1994; Gunter et al. 1997, 2000). However, relatively few studies have investigated the role that $\mathrm{CO}_{2}$ hydrate could play in trapping $\mathrm{CO}_{2}$ in cooler sediments. Some previous studies have considered that the relative stability of methane and $\mathrm{CO}_{2}$ hydrates might facilitate the trapping of $\mathrm{CO}_{2}$ as a hydrate whilst at the same time liberating methane (IEA GHG 2000; Goel 2006), whereas other studies have concentrated on just $\mathrm{CO}_{2}$ injection followed by $\mathrm{CO}_{2}$ hydrate formation (e.g. Kiode et al. 1997; House et al. 2006). Both approaches raise questions about our understanding of the processes involved and their inherent uncertainties. Where might storage of $\mathrm{CO}_{2}$ by these methods be possible? How will the hydrate interact with sediment grains and pore fluids? What are the rates and magnitudes of the trapping processes involved? How safe and secure will the $\mathrm{CO}_{2}$ hydrate be in the long term?

The study by Rochelle et al. (2009) takes a broad view of the possibilities for underground $\mathrm{CO}_{2}$ storage in cool sediments. It considers some of the beneficial trapping mechanisms that might be enhanced relative to more conventional $\mathrm{CO}_{2}$ storage at higher temperatures, such as the role of $\mathrm{CO}_{2}$ hydrate as both an immobile trapping phase and as a potential cap above a store of free-phase $\mathrm{CO}_{2}$. This approach is extended to consider where $\mathrm{CO}_{2}$ hydrate might be stable in sediments, with Camps et al. (2009) calculating the extent and thickness of $\mathrm{CO}_{2}$ hydrate and methane hydrate stability zones offshore western Scotland. Below the bed of the Faroe-Shetland Channel $\mathrm{CO}_{2}$ hydrate is predicted to be stable to a maximum depth of $345 \mathrm{~m}$, whereas methane hydrate has a greater maximum stability depth of $650 \mathrm{~m}$. Rochelle et al. (2009) use a similar approach to present preliminary modelling of regions offshore western Europe, which shows that large areas may have the potential for $\mathrm{CO}_{2}$ hydrate formation in deep-water sediments. These studies indicate that the storage of $\mathrm{CO}_{2}$ as a hydrate within sediments may present a viable future $\mathrm{CO}_{2}$ storage technology for some parts of Europe. However, they also highlight the importance of certain basic information when making predictions, such as the lack of detailed geothermal gradient data, which limits the extent to which detailed models and predictions can be made.

Much work remains to be undertaken to fully understand how $\mathrm{CO}_{2}$ hydrate can best contribute to underground storage. Kvamme et al. (2009) explore the possibilities of replacing original hydrate-bound hydrocarbons, such as methane, by 


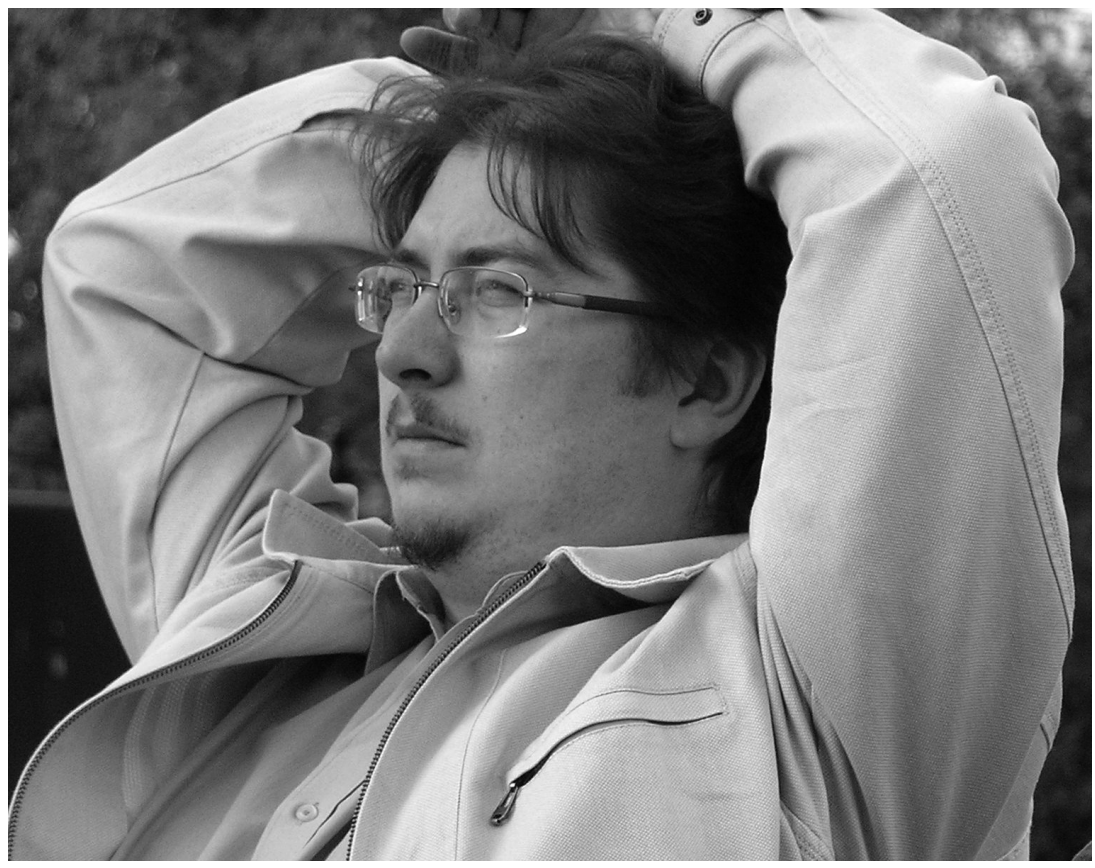

Fig. 1.

$\mathrm{CO}_{2}$ as hydrates of the latter hydrates are considerably more stable thermodynamically than methane hydrates. Technologies allowing two goals to be accomplished at the same time - safe storage of carbon dioxide in hydrate reservoirs, and in situ release of hydrocarbon gas - would offer enormous economic potential. It certainly would provide an opportunity for hydrate scientists to utilize their detailed knowledge to provide another novel technique to add to the portfolio of strategies that could help reduce emissions of anthropogenic $\mathrm{CO}_{2}$ to the atmosphere.

\section{Overview and conclusions}

What is encouraging about recent developments in hydrate science is the fact that, whilst great uncertainties about the potential environmental and economic impacts of hydrates remain, much new research is focusing on the key issues relating to hydrate sediment interaction. It now appears that we have left the period when hydrate research was dominated by studies of the distribution and setting of BSRs, and are now moving into one in which the primary physical questions about the physical setting of hydrates, and the processes that generated these, are uppermost. This is well illustrated by the papers in this volume. In the quest for a more detailed understanding of the distribution and stability of hydrates in sediments, a wide range of approaches have been developed, addressing questions from the microscopic to the global in scale. These have developed not only new methodologies, but also novel technologies, as may be seen in several of the papers here. As the science evolves, so do the questions and refocusing of subsequent research. As may be seen in these papers (e.g. Kleinberg 2009), those with an interest in the economic potential of hydrates are already re-prioritizing their exploration foci. Likewise, those whose interest lies in hydrates and climate are recognizing the great importance that relatively shallow, circum-polar hydrates, may have in controlling climate, and thus are fast considering how to address the research challenges in these areas.

The hydrate community have long-recognized the importance of inter-national, -institutional and -disciplinary research. However, whilst this may have been largely stimulated by the high costs of field campaigns in the past, it is increasingly apparent that there will be many benefits in developing integrated programmes addressing issues such as hydrate-sediment relationships. Many parties have the potential to unlock part, but only a part, of a large puzzle. By coming together, researchers should be able to answer some of the key questions about sediment-hosted gas hydrates, and their stability, more rapidly than if they had done this alone. 
Today there are many opportunities, for instance with the IODP, and establishment of observatories, to participate in joint programmes. It is important to recognize that, whilst the top-level objectives of different scientists are often different, many of the physical observations and models that come out of the research are generic, and will have widespread applicability. It is highly likely that many advances being developed by those establishing the economic development of hydrates (e.g. in the Nankai Trough), will also assist scientists who want to address some climate-related questions about methane release, or the potential for climate change mitigation through $\mathrm{CO}_{2}$ storage.

The meeting 'Sediment-Hosted Gas Hydrates: New Insights on Natural and Synthetic Systems' was useful in bringing together many leading edge scientists who are actively studying hydrate-sediment interactions and continuing the analysis of where the major uncertainties lie in relation to hydrate stability. The meeting marked a small, but definite, landmark in hydrate science, demonstrating the maturity of the science in some areas, and how measurements may be used to better quantify hazard or resource, as well as to new research trends. It is clear that hydrate research has a long, long, way to go before we can even confidently predict the global volume of hydrate. We look forward to watching what happens over the next decade - within which we expect to again focus on the primary interactions between hydrates and their host sediments.

\section{Dr Leonid L. Mazurenko, 1976-2007}

Dr Leonid Leonidovich Mazurenko was an enthusiastic participant of the International Conference 'Sediment-Hosted Gas Hydrates: New Insights on Natural and Synthetic Systems', upon which this volume is based. The work he presented at the meeting dealt with gas hydrates and hydrateforming fluids from gas venting sites in the Sea of Okhotsk as a part of the CHAOS Project. His paper on the subject in this volume is his final publication.

Leonid Mazurenko was born on 4 December, 1976 in Priozersk, Kazakhstan (USSR). He studied in the Department of Lithology at Moscow State University. In 1998, he went to St Petersburg, where he continued his education at St Petersburg State University and then was employed as an 'engineer-geologist' by the All Russia Research Institute for Geology and Mineral Resources of the Ocean (VNIIOkeangeologia). Leonid's career progressed as a 'engineer-geologist', scientist, senior scientist and head of the Laboratory for Gas Hydrate Geology in VNIIOkeangeologia.
Leonid was interested in and actively involved with research in submarine gas hydrates and related geochemical systems. The successful defence of his dissertation entitled 'Gas hydrate formation in submarine fluid discharge areas' earned him the Russian scientific degree of Candidate of Science in 2004 (equivalent to a Western PhD). He was one of the most prominent specialists in the Russian gas hydrate and fluid venting geochemical community, and was recognized internationally for his understanding of gas hydrate dynamics and formation mechanisms. He was at the beginning of a bright scientific career, and had already made important contributions to the understanding of gas hydrates and pore water chemistry for numerous of fluid venting areas. Amongst these were parts of the Black Sea, the Gulf of Cadiz (NE Atlantic), the Sea of Okhotsk and Lake Baikal.

Leonid was consistently highly energetic and cheerful, and always fully enjoyed life. He had an outstanding sense of humour and combined his research responsibilities and laboratory leadership roles with building friendships and taking good care of his family. His sudden death at the tragically young age of 30 came as a shock to his family and colleagues. He will be greatly missed by them, and his death is a big loss to the gas hydrate scientific community.

\section{References}

Anderson, R., Llamedo, C., Tohidi, B. \& Burgass, R. W. 2003. Experimental measurement of methane and carbon dioxide clathrate hydrate equilibria in mesoporous silica. Journal of Physical Chemistry B, 107, 3507-3514.

ANDERSon, R., Tohidi, B. \& Webber, J. B. W. 2009. Gas hydrate growth and dissociation in narrow pore networks: capillary inhibition and hysteresis phenomena. In: Long, D., Lovell, M. A., Rees, J. G. \& Rochelle, C. A. (eds) Sediment-Hosted Gas Hydrates: New Insights on Natural and Synthetic Systems. Geological Society, London, Special Publications, 319, 145-159.

Bachu, S., Gunter, W. D. \& Perkins, E. H. 1994. Aquifer disposal of $\mathrm{CO}_{2}$ : Hydrodynamic and mineral trapping. Energy Conversion and Management, 35, Q8 269-279.

BAKLID, A., KoRnø, L. R. \& OWREN, G. 1996. Sleipner Vest $\mathrm{CO}_{2}$ disposal, $\mathrm{CO}_{2}$ injection into a shallow underground aquifer. Society of Petroleum Engineers, 36600, 269-277.

Brooks, J. M. \& Bryant, W. R. 1985. Geological and Geochemical Implications of Gas Hydrates in the Gulf of Mexico. Final report to Department of Energy, Morgantown Energy Technology Centre, West Virginia.

CAMPS, A. P. 2007. Hydrate formation in near surface ocean sediments. Unpublished $\mathrm{PhD}$, Department of Geology, University of Leicester. 
Camps, A. P., Long, D., Rochelle, C. A. \& Lovell, M. A. 2009. Mapping hydrate stability zones offshore Scotland. In: LonG, D., Lovell, M. A., ReES, J. G. \& Rochelle, C. A. (eds) Sediment-Hosted Gas Hydrates: New Insights on Natural and Synthetic Systems. Geological Society, London, Special Publications, 319, 81-91.

Clennell, M. B., Hovland, M., Booth, J. S., Henry, P. \& WinTERS, W. J. 1999. Formation of natural gas hydrates in marine sediments. Part 1: Conceptual model of gas hydrate growth conditioned by host sediment properties. Journal of Geophysical Research B, 104, 22985-23003.

Collett, T. S. 1983. Detection and evaluation of natural gas hydrates from well logs, Prudhoe Bay, Alaska. Proceedings of the 4th International Conference on Permafrost, Fairbanks, AL, 169-174.

Collett, T. S. \& KuUsKraA, V. A. 1998. Hydrates contain vast store of world gas resources. Oil and Gas Journal, 96, 90-95.

Cook, A. E. \& GoldberG, D. 2007. Gas hydrate filled fracture distribution, eastern Indian continental margin. American Geophysical Union Fall Meeting, San Francisco, CA, AN: OS11C-04.

Davies, R. J. \& CARTwright, J. A. 2002. A fossilised Opal A to C/T transformation on the northeast Atlantic margin. Basin Research, 14, 467-486.

DAVY, H. 1811. On some of the combinations of oxy-muriatic gas and oxygen, and on the chemical relations of the principles to inflammable bodies. Philosophical Transactions of the Royal Society, London, 101, 1-35.

Dickens, G. R., Castillo, M. M. \& Walker, J. C. G. 1997. A blast of gas in the latest Paleocene: Simulating first-order effects of massive dissociation of oceanic methane hydrate. Geology, 25, 259-262.

Dvorkin, J., Helgerud, M., Waite, W., Kirby, S. \& NUR, A. 2000. Introduction to physical properties and elasticity models. In: MAX, M. D. (ed.) Natural Gas Hydrate in Oceanic and Permafrost Environments, Kluwer Academic, Dordrecht, 245-260.

Eaton, M. W., Jones, K. W. \& Mahajan, D. 2009. Mimicking natural systems: methane hydrate formation/decomposition in depleted sediments. In: Long, D., Lovell, M. A., ReEs, J. G. \& Rochelle, C. A. (eds) Sediment-Hosted Gas Hydrates: New Insights on Natural and Synthetic Systems. Geological Society, London, Special Publications, 319, 121-130.

ECKER, C., Dvor KIN, J. \& NUR, A. 2000. Estimating the amount of gas hydrate and free gas from marine seismic data. Geophysics, 65, 565-573.

ERwin, D. H. 1994. The Permo-Triassic extinction. Nature, 367, 231-236.

Finley, P. \& Krason, J. 1986. Geological Evolution and Analysis of Confirmed or Suspected Gas Hydrate Localities: Basin Analysis, Formation and Stability of Gas Hydrates in the Middle America Trench. US Department of Energy, DOE/MC/ 21181-1950, 9.

GoEL, N. 2006. In situ methane hydrate dissociation with carbon dioxide sequestration: Current knowledge and issues. Journal of Petroleum Science and Engineering, 51, 169-184.
Gunter, W. D., Wiwchar, B. \& Perkins, E. H. 1997. Aquifer disposal of $\mathrm{CO}_{2}$-rich greenhouse gases: Extension of the time scale of experiment for $\mathrm{CO}_{2}$ sequestering reactions by geochemical modelling. Mineralogy and Petrology, 59, 121-140.

Gunter, W. D., Perkins, E. H. \& Hutcheon, I. 2000. Aquifer disposal of acid gases: Modelling of waterrock reactions for trapping of acid wastes. Applied Geochemistry, 15, 1085-1095.

Gunter, W. D., Perkins, E. H. \& McCann, T. J. 1993. Aquifer disposal of $\mathrm{CO}_{2}$-rich gases: Reaction design for added capacity. Energy Conversion Management, Q3 34, 941-948.

HAMMERSCHMIDT, E. G. 1934. Formation of gas hydrates in natural gas transmission lines. Industrial Engineering Chemistry, 26, 851-855.

HAQ, B. U. 1988. Natural gas hydrates: Searching for the longterm climatic and slope-stability records. In: HENRIET, J.-P. \& Mienert, J. (eds) Gas Hydrates: Relevance to World Margin Stability and Climate Change. Geological Society, London, Special Publications, 137, 303-318.

Henry, P., Thomas, M. \& Clennell, M. B. 1999. Formation of natural gas hydrates in marine sediments. Part 2: Thermodynamic calculations of stability conditions in porous sediments. Journal of Geophysical Research B, 104, 23005-23022.

House, K. Z., Schrag, D. P., Harvey, C. F. \& LACKNeR, K. S. 2006. Permanent carbon dioxide storage in deep-sea sediments. Proceedings of the National Academy of Sciences, 103, 12291-12295.

IEA GHG. 2000. Issues Underlying the Feasibility of Storing $\mathrm{CO}_{2}$ as Hydrate Deposits. IEA Greenhouse Gas R\&D Programme Report PH3/25.

INAGAKI, F., NUNOURA, T. ET AL. 2006. Biogeographical distribution and diversity of microbes in methane hydrate-bearing deep marine sediments on the Pacific Ocean Margin. Proceedings of the National Academy of Sciences, 103, 2815-2820.

IPCC. 1990. First assessment report. Published by the IPCC. World Wide Web Address: http://www.ipcc. ch/ipccreports/assessments-reports.htm.

IPCC. 1995. Second assessment report: Climate change. World Wide Web Address: http://www.ipcc.ch/ ipccreports/assessments-reports.htm.

IPCC. 2001. Third assessment report: Climate change. World Wide Web Address: http://www.ipcc.ch/ ipccreports/assessments-reports.htm.

IPCC. 2007. Fourth assessment report: Climate change. World Wide Web Address: http://www.ipcc.ch/ ipccreports/assessments-reports.htm.

Kiode, H., TAKAhashi, M. ET AL. 1997. Hydrate formation in sediments in the sub-seabed disposal of $\mathrm{CO}_{2}$. Energy, 22, 279-283.

Klapp, S. A., Klein, H. \& Kuns, W. F. 2009. Gas hydrate crystallite size investigations with high-energy synchrotron radiation. In: LONG, D., LOVELL, M. A., Rees, J. G. \& Rochelle, C. A. (eds) SedimentHosted Gas Hydrates: New Insights on Natural and Synthetic Systems. Geological Society, London, Special Publications, 319, 161-170.

Klauda, J. B. \& SANDleR, S. I. 2005. Global distribution of methane hydrate in ocean sediment. Energy and Fuels, 19, 459-470. 
KLEINBERG, R. L. 2009. Exploration strategy for economically significant accumulations of marine gas hydrate. In: LoNG, D., LOVElL, M. A., ReEs, J. G. \& Rochelle, C. A. (eds) Sediment-Hosted Gas Hydrates: New Insights on Natural and Synthetic Systems. Geological Society, London, Special Publications, 319, 21-28.

Kleinberg, R. L., Flaum, C. ET AL. 2003. Deep sea NMR: Methane hydrate growth habit in porous media and its relationship to hydraulic permeability, deposit accumulation, and submarine slope stability. Journal Geophysical Research, 108, 2508.

KoH, C. A. \& SlOAN, D. E. 2007. Natural gas hydrates: Recent advances and challenges in energy and environmental applications. American Institute of Chemical Engineers Journal, 53, 1636-1643.

KRUll, S. J. \& Retallack, J. R. 2000. ${ }^{13} \mathrm{C}$ depth profiles from paleosols across the Permian-Triassic boundary: Evidence for methane release. GSA Bulletin, 112, 1459-1472.

Kvamme, B., Graue, A., Buanes, T., Kuznetsova, T. \& ERSLAND, G. 2009. Effects of solid surfaces on hydrate kinetics and stability. In: LONG, D., Lovell, M. A., Rees, J. G. \& Rochelle, C. A. (eds) Sediment-Hosted Gas Hydrates: New Insights on Natural and Synthetic Systems. Geological Society, London, Special Publications, 319, $131-144$.

KVEnVOLDEN, K. A. 1998. A primer on the geological occurrence of gas hydrate. In: HENRIET, J.-P. \& Meinerts, J. (eds) Gas Hydrates: Relevance to World Margin Stability Change. Geological Society, London, Special Publications, 137, 9-30.

KVEnVOLDEN, K. A. 2000. Gas hydrate and humans. In: Holder, G. D. \& BishnoI, P. R. (eds) Gas Hydrates: Challenges for the Future. Annals of the New York Academy of Sciences, 912, 17-22.

Kvenvolden, K. A. \& McDonald, T. J. 1985. Gas Hydrates of the Middle America Trench DSDP Leg 84. Initial Reports, DSDP 84. US Government Printing Office, Washington, DC, 367-375.

LANCELOT, Y. \& EWING, J. I. 1972. Correlation of natural gas zonation and carbonate diagenesis in Tertiary sediments from the north-west Atlantic. In: Hollister, C. D., Ewing, J. I. ET AL. (eds) Initial Reports, DSDP 11. US Government Printing Office, Washington, DC, 791-799.

Levitus, S., Antonov, J. \& Boyer, T. 2005. Warming of the world ocean, 1955-2003. Geophysical Research Letters, 32, L02604.

Llamedo, M., Anderson, R. \& Tohidi, B. 2004. Thermodynamic prediction of clathrate hydrate dissociation conditions in mesoporous media. American Mineralogist, 89, 1264-1270.

Maclennan, J. \& Jones, S. M. 2006. Regional uplift, gas hydrate dissociation and the origins of the Paleocene-Eocene thermal maximum. Earth and Planetary Science Letters, 245, 65-80.

Makogon, Y. F., Holditch, S. A. \& MAKOgON, T. Y. 2007. Natural gas-hydrates - a potential energy source for the 21st century. Journal of Petroleum Science and Engineering, 56, 14-31.

Malk, Q. M. \& Islam, M. R. 2000. $\mathrm{CO}_{2}$ Injection in the Weyburn Field of Canada: Optimization of
Enhanced Oil Recovery and Greenhouse Gas Storage with Horizontal Wells. Society of Petroleum Engineers, $\mathbf{5 9 3 2 7}$

Malone, R. 1985. Gas Hydrates Topical Report, DOE/METC/SP-218 (DE85001986). Department of Energy, Morgantown Energy Technology Center, USA.

Mazurenko, L. L., Matveeva, T. V. et AL. 2009. Gas hydrate forming fluids on the NE Sakhalin slope, Sea of Okhotsk. In: LONG, D., LOVELL, M. A., REES, J. G. \& Rochelle, C. A. (eds) Sediment-Hosted Gas Hydrates: New Insights on Natural and Synthetic Systems. Geological Society, London, Special Publications, 319, 51-72.

McGee, T., Macelloni, L. ET AL. 2009. Hydrocarbon gas hydrates in sediments of the Mississippi Canyon area, Northern Gulf of Mexico. In: LonG, D., Lovell, M. A., Rees, J. G. \& Rochelle, C. A. (eds) Sediment-Hosted Gas Hydrates: New Insights on Natural and Synthetic Systems. Geological Society, London, Special Publications, 319, 29-49.

Milkov, A. V. 2003. Global estimates of hydrate-bound gas in marine sediments: How much is really out there? Earth-Science Reviews, 66, 183-197.

Milkov, A. V. \& SASSEN, R. 2001. Estimate of gas hydrate resource, northwestern Gulf of Mexico continental slope. Marine Geology, 179, 71-83.

Miller, S. L. 1974. The nature and occurrence of clathrate hydrates. In: KAPLAN, I. R. (ed.) Natural Gases in Marine Sediments. Plenum, New York, 151-177.

Minshull, T. A. \& ChAnd, S. 2009. The pore-scale distribution of sediment-hosted hydrates: evidence from effective medium modelling of laboratory and borehole seismic data. In: Long, D., Lovell, M. A., Rees, J. G. \& Rochelle, C. A. (eds) SedimentHosted Gas Hydrates: New Insights on Natural and Synthetic Systems. Geological Society, London, Special Publications, 319, 93-101.

RCEP. 2000. Energy - the Changing Climate. Twentysecond report of the Royal Commission on Environmental Pollution, Cm. 4749.

Riedel, M., Collett, T. S., Malone, M. J. \& The EXPEDITION 311 Scientists. 2006. Proceedings of IODP 311. Integrated Ocean Drilling Program Management International, Inc., Washington, DC.

Riedel, M., Collett, T., Malone, M. J. \& IODP EXPEDITION 311 SCIENTISTS. 2009. Gas hydrate drilling transect across northern Cascadia margin - IODP Expedition 311. In: LONG, D., LOVELL, M. A., REES, J. G. \& Rochelle, C. A. (eds) Sediment-Hosted Gas Hydrates: New Insights on Natural and Synthetic Systems. Geological Society, London, Special Publications, 319, 11-19.

Rochelle, C. A., CAmps, A. P. et AL. 2009. Can $\mathrm{CO}_{2}$ hydrate assist in the underground storage of carbon dioxide? In: LonG, D., Lovell, M. A., Rees, J. G. \& Rochelle, C. A. (eds) Sediment-Hosted Gas Hydrates: New Insights on Natural and Synthetic Systems. Geological Society, London, Special Publications, 319, 171-183.

SAKAI, H., GAMO, T. ET AL. 1990. Venting of carbon dioxide-rich fluid and hydrate formation in mid-Okinawa trough backarc basin. Science, 248, 1093-1096. 
SLOAN, E. D. JR. 1998. Clathrate Hydrates of Natural Gases. Marcel Dekker, New York.

SLuis, A. 2006. Global Change During the PaleoceneEocene Thermal Maximum. $\mathrm{PhD}$ thesis, Utrecht University.

Soloviev, V. \& Ginsburg, G. D. 1994. Formation of submarine gas hydrates. Bulletin of the Geological Society of Denmark, 41, 86-94.

SWART, R. 2009. Hydrate occurrences in the Namibe Basin, offshore Namibia. In: LONG, D., LOvelL, M. A., Rees, J. G. \& Rochelle, C. A. (eds) Sediment-Hosted Gas Hydrates: New Insights on Natural and Synthetic Systems. Geological Society, London, Special Publications, 319, 73-80.

Tinivella, U., Loreto, M. F. \& Accaino, F. 2009. Regional versus detailed velocity analysis to quantify hydrate and free gas in marine sediments: The South Shetland Margin case study. In: LONG, D., Lovell, M. A., Rees, J. G. \& Rochelle, C. A. (eds) Sediment-Hosted Gas Hydrates: New Insights on Natural and Synthetic Systems. Geological Society, London, Special Publications, 319, 103-119.

Tréhu, A. M., Bohrmann, G., Torres, M. E. \& Colwell, F. S. (eds). 2002. Proceedings of the Ocean Drilling Program, Scientific Results, 204.

TréHu, A. M., Long, P. E. ET AL. 2004. Three dimensional distribution of gas hydrate beneath southern hydrate ridge: Constraints from ODP Leg
204. Earth and Planetary Science Letters, 222, $845-862$.

White, D. J., Burrowes, G. ET AL. 2004. Greenhouse gas sequestration in abandoned oil reservoirs: The International Energy Agency Weyburn pilot project. GSA Today, 14, 4-10.

WHITE, R. V. 2002. Earth's biggest 'whodunnit': Unravelling the clues in the case of the end. Philosophical Transactions of the Royal Society, London, 360, 2963-2985.

WiLson, M. \& MoneA, M. (eds). 2004. IEA GHG Weyburn $\mathrm{CO}_{2}$ Monitoring \& Storage Project Summary Report 2000-2004. Proceedings of the 7th International Conference on Greenhouse Gas Control Technologies, 5-9 September 2004, Vancouver, Canada, III. Petroleum Technology Research Centre, Regina.

YAKUSHEV, V. 2004. Intrapermafrost gas hydrates at the north of west Siberia. AAPG Hedberg Conference, Gas Hydrates: Energy Resource Potential and Associated Geologic Hazards, 12-16 September 2004, Vancouver.

Yeframova, A. G. \& Zhizhchenko, B. P. 1975. Occurrence of crystal hydrates of gases in the sediments of modern marine basins. Doklady, Earth Sciences Section, 214, 219-220.

ZaCHOS, J. C., RÖHL, U. ET AL. 2005. Rapid acidification of the ocean during the Paleocene-Eocene thermal maximum. Science, 308, 1611-1615. 